\title{
Correlation of visual inspection with cytological and histopathological findings in cervical neoplasia
}

\author{
Sherpa $\mathrm{P}^{1}$, Pant $\mathrm{AD}^{2}$ \\ ${ }^{I}$ Department of Pathology, Patan Academy of Health Sciences, Lalitpur, Nepal. \\ ${ }^{2}$ Department of Pathology, Institute of Medicine, Kathmandu, Nepal.
}

\section{Keywords: \\ Cervical neoplasia; Papanicolaou smear; Visual inspection with acetic acid}

\begin{abstract}
Background: Cervical cancer is one of the commonest malignancies and a leading cause of morbidity and mortality among women. The aim of this study was to evaluate the diagnostic value of Papanicolaou (PAP) smear and visual inspection with acetic acid as methods of cervical cancer screening.

Materials and Methods: This was an observational cross-sectional study conducted from the period of 2068.11.01 to 2069.11.01. The study population consisted of women with histologically confirmed cervical intraepithelial neoplasia or invasive carcinoma who had undergone prior PAP smear.
\end{abstract}

Result: During the study period 160 patients underwent both PAP smear and cervical biopsy. Of these patients, 49 had a histological diagnosis of cervical intraepithelial neoplasia or invasive carcinoma. The histopathological and cytological diagnoses were compared. visual inspection with acetic acid status was available for 31 of the 49 cases. The sensitivity of PAP smear was $61 \%$, specificity $97 \%$, Positive predictive value $91 \%$, negative predictive value $85 \%$ and diagnostic accuracy $86 \%$ for detection of cervical neoplasia. Visual inspection with acetic acid had a sensitivity of $74 \%$, specificity $48 \%$, Positive predictive value $64 \%$, Negative predictive value $60 \%$ and diagnostic accuracy of $63 \%$. Combining the two procedures increased sensitivity by $26 \%$, Negative predictive value by $11 \%$ and diagnostic accuracy by $2 \%$.

Conclusion: PAP smear has a higher specificity, Positive predictive value, Negative predictive value and diagnostic accuracy but lower sensitivity than Visual inspection with acetic acid. Visual inspection with acetic acid by itself is not an effective screening method. A combination of PAP smear and Visual inspection with acetic acid can ensure adequate screening of cervical neoplasia.

\section{INTRODUCTION}

Carcinoma of the uterine cervix is one of the most common cancer in women worldwide. It is one of the leading causes

\author{
Correspondence: \\ Dr. Palzum Sherpa, MBBS, MD \\ Department of Pathology \\ Patan Academy of Health Sciences, Lalitpur, Nepal \\ E-mail:palzumsherpa@pahs.edu.np
}

of cancer death among women. The estimated new cases worldwide per year are 500,000 of which $79 \%$ occur in the developing countries. ${ }^{1}$ Cervical cancer is preventable and potentially curable if detected at an early stage using proper screening tools. ${ }^{2}$ Early detection, followed by appropriate therapy could make a very large difference to survival rates. ${ }^{3}$ Cervical screening in many respects is an ideal screening test. It has a defined pre-malignant phase of many years, which allows repeated tests to significantly reduce the 
Table 1: Comparison of results of PAP smear, VIA and their combination

\begin{tabular}{|c|c|c|c|c|c|c|c|c|c|c|c|c|c|c|}
\hline \multicolumn{5}{|c|}{ Biopsy } & \multicolumn{5}{|c|}{ Biopsy } & \multicolumn{5}{|c|}{ Biopsy } \\
\hline & & $+v e$ & -ve & Total & & & $+v e$ & -ve & Total & & & $+v e$ & -ve & Total \\
\hline \multirow[b]{2}{*}{ PAP } & $+v e$ & 30 & 3 & 33 & \multirow{2}{*}{ VIA } & $+v e$ & 23 & 13 & 36 & \multirow{2}{*}{$\begin{array}{l}\text { PAP } \\
\text { and } \\
\text { VIA }\end{array}$} & $+v e$ & 27 & 15 & 42 \\
\hline & -ve & 19 & 108 & 127 & & -ve & 8 & 12 & 20 & & -ve & 4 & 110 & 114 \\
\hline Total & & 49 & 111 & 160 & Total & & 31 & 25 & 56 & Total & & 31 & 125 & 156 \\
\hline
\end{tabular}

impact of false negative rate. ${ }^{4}$ Depending on the resources available, there are a number of screening methods like visual inspection tests, PAP smear and HPV DNA tests.

The current study is aimed at finding out the diagnostic accuracy of PAP smear at a tertiary level hospital considering histopathology results as the gold standard. The diagnostic value of PAP smear is also compared with the results of VIA, in available cases in order to determine if VIA can be used as a primary screening tool in resource limited settings. This study intends to evaluate and compare the commonly used screening modalities so that we can help clinicians reach to an early diagnosis and treatment of cervical neoplasia, thus giving women an opportunity for a better quality of life.

\section{MATERIALS AND METHODS}

This was a prospective study carried out over a period of 1 year from 2068.11.01 to 2069.11.01 at the Department of Pathology, Institute of Medicine, Tribhuvan University Teaching Hospital, Kathmandu, Nepal. Approval of the study protocol by the institutional review board of Institute of Medicine was obtained.

The study population consisted of women with histologically confirmed cervical intraepithelial neoplasia or invasive carcinoma who had undergone a prior PAP smear test. However, women with previous history of cervical cancer were excluded from the study. Detailed clinical data was obtained and noted in a structured proforma. Data was analyzed using the Statistical Package for Social Sciences (SPSS) version 16.

\section{RESULTS}

During the study period, a total of 160 patients underwent both PAP smear and cervical biopsy. Out of these 160 cases, 49 had positive results in biopsy specimen and were included in the study. Among the 49 cases, 30 had positive result and 19 had negative result in PAP smear. Three patients had positive PAP smear with negative biopsy results and 108 had negative results in both. A total of 56 patients had underwent both VIA and cervical biopsy. Among them, 31 patients had positive result in biopsy (23 VIA positive and 8 VIA negative) and were included in the study. Thirteen patients were VIA positive with negative biopsy and 12 had negative results in both (Table 1).

Minimum age of the patient was 23 years and the maximum age was 82 years. The mean age of the patient was 42 years.
Table 2: Relation between age and cervical neoplasia

\begin{tabular}{lccc}
\hline Age Group & LSIL & HSIL & SCC \\
\hline 21-30 years & 4 & 2 & 1 \\
31-40 years & 8 & 9 & 1 \\
41-50 years & 13 & 3 & 0 \\
51-60 years & 1 & 1 & 2 \\
61-70 years & 0 & 0 & 3 \\
71-80 years & 0 & 0 & 0 \\
81-90 years & $\mathbf{0}$ & $\mathbf{1}$ & $\mathbf{0}$
\end{tabular}

HSIL was more common in the age group 31-40 years, LSIL in 41-50 years and squamous cell carcinoma in 61-70 years (Table 2). A significant statistical association of cervical intraepithelial lesion and malignancy with parity was established with a p-value of 0.024 . Only $1(2 \%)$ nulliparous woman had cervical neoplasm whereas 25 (51.02\%) women with cervical neoplasm had three or more children.

The comparison of the histopathological diagnoses with PAP smear and VIA are tabulated (Table $3 \& 4$ ). The sensitivity of PAP smear was $61 \%$, specificity $97 \%$, positive predictive value (PPV) 91\%, negative predictive value (NPV) $85 \%$ and diagnostic accuracy $86 \%$ for detection of cervical neoplasia. VIA had a sensitivity of $74 \%$, specificity $48 \%$, PPV $64 \%$, NPV $60 \%$ and diagnostic accuracy of $63 \%$. Combining the two procedures increased sensitivity by $26 \%$, NPV by $11 \%$ and diagnostic accuracy by $2 \%$ (Table 5 ).

\section{DISCUSSION}

The present study had a spectrum of patients ranging from 23 to 82 years of age. Mean age of the patient was 42 years. Maximum frequency $(36.7 \%)$ was found in the age group 31-40 years, closely followed by $41-50$ years of women constituting $32.7 \%$. Similar results were found in studies performed by Goel et $\mathrm{al}^{5}$, Dhakal et $\mathrm{al}^{6}$ and Boicea et al. ${ }^{7}$ Thus, since cervical neoplasia is more common between 31 50 years, the screening programs should target women in this age group.

The value of PAP smear in screening for cervical cancer has long been established. VIA is an alternative method especially suited for low resource settings. The sensitivity of PAP smear in our study was $61.2 \%$ which is lower than that of VIA (74.1\%). The specificity of PAP smear was $97.2 \%$ whereas that of VIA was only $48.0 \%$. The PPV of PAP smear was $90.9 \%$, NPV was $85.0 \%$ and diagnostic accuracy was $86.2 \%$. VIA had a PPV of $63.8 \%$, NPV of 
Table 3: Comparison between PAP smear and biopsy results

\begin{tabular}{lcccccccc}
\hline \multirow{2}{*}{ Histopathologic diagnosis } & \multicolumn{7}{c}{ Papanicolaou smear results } \\
\cline { 2 - 9 } & Negative & ASCUS & AGUS & LSIL & HSIL & SCC & $\begin{array}{c}\text { Unsatisfactory for evalu- } \\
\text { ation }\end{array}$ & $\begin{array}{c}\text { Total } \\
\text { LSIL }\end{array}$ \\
HSIL & 14 & 3 & 1 & 7 & 1 & 0 & 0 & 26 \\
Squamous cell carcinoma & 5 & 2 & 1 & 1 & 6 & 0 & 1 & 16 \\
Total & 0 & 0 & 0 & 0 & 6 & 1 & 0 & $\mathbf{1}$ \\
& $\mathbf{1 9}$ & $\mathbf{5}$ & $\mathbf{2}$ & $\mathbf{8}$ & $\mathbf{1 3}$ & $\mathbf{1}$ & $\mathbf{4 9}$
\end{tabular}

Table 4: Comparison of VIA results and biopsy

\begin{tabular}{lcccc}
\hline \multirow{2}{*}{$\begin{array}{l}\text { Histopathologic } \\
\text { diagnosis }\end{array}$} & \multicolumn{4}{c}{ Visual inspection with acetic acid results } \\
\cline { 2 - 5 } LSIL & Positive & Negative & $\begin{array}{c}\text { Not } \\
\text { available }\end{array}$ & Total \\
\hline HSIL & 10 & 6 & 10 & 26 \\
$\begin{array}{l}\text { Squamous cell } \\
\text { carcinoma }\end{array}$ & 4 & 2 & 5 & 16 \\
Total & $\mathbf{2 3}$ & $\mathbf{8}$ & $\mathbf{1 8}$ & $\mathbf{4 9}$ \\
\hline
\end{tabular}

$60.0 \%$ and diagnostic accuracy of $62.5 \%$.

This finding is consistent with that of Singh et al who reported sensitivity of $70.0 \%$ for PAP smear and $93.1 \%$ for VIA, specificity of $97.2 \%$ for PAP smear and $86.8 \%$ for VIA. They reported PPV of $51.2 \%$ for PAP smear, $22.1 \%$ for VIA and NPV of $97.0 \%$ and $99.0 \%$ respectively. The study suggested that due to the high sensitivity of VIA, the test could be valuable in detection of precancerous lesions of the cervix. ${ }^{8}$

The sensitivity of PAP smear and VIA was found to be $50.0 \%$ and $96.7 \%$ and specificity was $97.0 \%$ and $36.4 \%$ in a study done by Goel et al. PPV of PAP smear was $97.5 \%$ and VIA was $58.0 \%$ and NPV of $96.09 \%$ and $99.7 \%$ were obtained respectively. This study concluded that the main limitation of VIA is a high rate of false positive results, which may lead to overtreatment if a "see and treat" policy is applied. ${ }^{5}$

A study by Consul et al reported that both PAP smear and VIA had equal sensitivity of $84.2 \%$. However, PAP smear showed specificity of $62.1 \%$ and VIA of $55.2 \%$. This study also stated that VIA may find a place as an alternative low resource screening tool. ${ }^{9}$

Table 5: Diagnostic value of PAP smear, VIA and their combination

\begin{tabular}{lccc}
\hline & $\begin{array}{c}\text { PAP } \\
\text { smear }\end{array}$ & VIA & $\begin{array}{c}\text { Combined PAP } \\
\text { smear and VIA }\end{array}$ \\
\hline Sensitivity & $61.2 \%$ & $74.1 \%$ & $87.0 \%$ \\
\hline $\begin{array}{l}\text { Specificity } \\
\text { Positive Predictive }\end{array}$ & $97.2 \%$ & $48.0 \%$ & $88.0 \%$ \\
$\begin{array}{l}\text { value } \\
\begin{array}{l}\text { Negative } \\
\text { Predictive value }\end{array}\end{array}$ & $90.9 \%$ & $63.8 \%$ & $64.2 \%$ \\
$\begin{array}{l}\text { Diagnostic } \\
\text { accuracy }\end{array}$ & $86.2 \%$ & $62.5 \%$ & $96.4 \%$ \\
\hline
\end{tabular}

Similarly, higher sensitivity and lower specificity of VIA compared to PAP smear was shown in a study performed by Bhatla et al who found PAP smear to be $50.0 \%$ sensitive, VIA as $100.0 \%$ sensitive and HPV testing as $85.7 \%$ sensitive. Specificity of $98.9 \%$ for PAP smear, $53.3 \%$ for VIA and $89.7 \%$ for HPV testing were reported.10 In a study done by Mayrand et al, PAP smear was 55.4\% sensitive and 96.8\% specific whereas HPV testing was 94.6\% sensitive and $94.1 \%$ specific. This study concluded that a shift from cellular to viral tests, coupled with education and vaccination will contribute to a more efficient control on cervical cancer. ${ }^{11}$

Vedantham et al found that among control group VIA positivity was $15.5 \%$ in women with inflammation and $6.1 \%$ in women without inflammation with a $p$ value of $<0.001 .^{12}$ Davis et al suggested that women with cervicitis were twice as likely to have a positive VIA result as women without cervicitis. ${ }^{13}$ In a similar fashion, inflammation could also have contributed to the false positive VIA results observed in our study.

In our study, we also tried to find out whether the combination of PAP smear and VIA improves the diagnostic accuracy of screening for cervical cancer. On combining the two procedures, the sensitivity increased by $26 \%$, NPV by $11 \%$ and diagnostic accuracy by $2 \%$. However, the specificity decreased by $9 \%$ and PPV by $26 \%$. Our results showed an overall improvement in the performance of the screening tests by using the two methods in combination. Our results are in concordance with studies done by Consul et $\mathrm{al}^{9}$, Denny et $\mathrm{al}^{14}$ and Sankarnarayan et $\mathrm{al}^{15}$, all of which demonstrated that when used in combination PAP smear and VIA had a much better diagnostic performance than each test alone.

\section{CONCLUSION}

PAP smear has a higher specificity, PPV, NPV and diagnostic accuracy but lower sensitivity than VIA. The findings of our study shows that VIA by itself is not an effective screening method and further actions based only on its result may prove unnecessary for a number of patients. A combination of PAP smear and VIA can ensure adequate screening of cervical neoplasia.

\section{REFERENCES}

1. Wells M OA, Crum CP, Franceschi, Tommasino M. Tumors of 
uterine cervix. Lyon, France: IARC press; 2003.

2. Hegde D, Shetty H, Shetty PK, Rai S. Diagnostic value of acetic acid comparing with conventional Pap smear in the detection of colposcopic biopsy-proved CIN. J Cancer Res Ther. 2011;7:454-8. Crossref

3. ACOG Practice Bulletin: clinical management guidelines for obstetrician-gynecologists. Number 45, August 2003. Cervical cytology screening (replaces committee opinion 152, March 1995). Obstetrics and gynecology. 2003;102:417-27. Crossref

4. Bhanot UK ML, Mital UP. Need for uniform system of reporting cervical/vaginal cytologic smear. J Nepal Med Assoc 2002;4:89-94.

5. Goel A, Gandhi G, Batra S, Bhambhani S, Zutshi V, Sachdeva P. Visual inspection of the cervix with acetic acid for cervical intraepithelial lesions. International journal of gynaecology and obstetrics: the official organ of the International Federation of Gynaecology and Obstetrics. 2005;88:25-30. Crossref

6. Dhakal HP, Pradhan M. Histological pattern of gynecological cancers. J Nepal Med Assoc. 2009;48:301-5. Crossref

7. Boicea A, Patrascu A, Surlin V, Iliescu D, Schenker M, Chiutu L. Correlations between colposcopy and histologic results from colposcopically directed biopsy in cervical precancerous lesions. Rom J Morphol Embryol. 2012;53:735-41. Crossref

8. Singh KN, More S. Visual inspection of cervix with acetic acid in early diagnosis of cervical intraepithelial neoplasia and early cancer cervix. J Obstet Gynecol India 2010;60:55-60. Crossref
9. Consul S, Agrawal A, Sharma H, Bansal A, Gutch M, Jain N. Comparative study of effectiveness of Pap smear versus visual inspection with acetic acid and visual inspection with Lugol's iodine for mass screening of premalignant and malignant lesion of cervix. Indian J Med Paediatr Oncol. 2012;33:161-5. Crossref

10. Bhatla N, Mukhopadhyay A, Kriplani A, et al. Evaluation of adjunctive tests for cervical cancer screening in low resource settings. Indian J Cancer 2007;44:51-5. Crossref

11. Mayrand MH, Duarte-Franco E, Rodrigues I, Walter SD, Hanley J, Ferenczy A, et al. Human papillomavirus DNA versus Papanicolaou screening tests for cervical cancer. N Engl J Med 2007;357:1579-88. Crossref

12. Vedantham H, Silver MI, Kalpana B, et al. Determinants of VIA (Visual Inspection of the Cervix After Acetic Acid Application) positivity in cervical cancer screening of women in a peri-urban area in Andhra Pradesh, India. Cancer Epidemiol Biomarkers Prev 2010;19:1373-80. Crossref

13. Davis-Dao CA, Cremer M, Felix J, Cortessis VK. Effect of cervicitis on visual inspection with acetic acid. J Low Genit Tract Dis. 2008;12:282-6. Crossref

14. Denny L. The prevention of cervical cancer in developing countries. BJOG 2005;112:1204-12. Crossref

15. Sankaranarayanan R WR. A practical manual on visual screening for cervical neoplasia. France: IARC; 2003. Crossref 